\title{
Improved monitoring framework for local planning in the water, sanitation and hygiene sector: from data to decision-making
}

Ricard Giné Garriga (corresponding author)

Engineering Sciences \& Global Development - ESc\&GD, University Research Institute for Sustainability Science and Technology, Universitat Politècnica de Catalunya, Spain Campus Nord - Edifici VX (Vèrtex) - Plaça Eusebi Güell, 6. 08034 Barcelona, Spain Phone: (+34) 4054375

Email: ricard.gine@upc.edu

Alejandro Jiménez Fdez. de Palencia

Stockholm International Water Institute, Sweden

E-mail: Alejandro.Jimenez@siwi.org

Agustí Pérez Foguet

Dept. of Applied Mathematics III, Engineering Sciences \& Global Development ESc\&GD, University Research Institute for Sustainability Science and Technology, Civil Engineering School, Universitat Politècnica de Catalunya

Email: agusti.perez@upc.edu

To cite this article: Giné Garriga R, Jiménez Fdez. de Palencia A, Pérez Foguet A. (2015) Improved monitoring framework for local planning in the water, sanitation and hygiene sector: From data to decision-making. Sci. Total Environ. 526:204-214.

To link to this article: $h$ ttp://dx.doi.org/10.1016/j.scitotenv.2015.04.078

Free access (until June 17, 2015): http://authors.elsevier.com/a/1QxWe 17GgFvyL 


\section{Abstract}

Today, a vast proportion of people still lack a simple pit latrine and a source of safe drinking water. To help end this appalling state of affairs, there is a pressing need to provide policymakers with evidences in which base effective planning, targeting and prioritization. Two major challenges often hinder this process: i) lack of reliable data to identify which areas are most in need; and ii) inadequate instruments for decision-making support.

In tackling previous shortcomings, this paper proposes a monitoring framework to compile, analyse, interpret and disseminate water, sanitation and hygiene information. In an era of decentralization, where decision-making moves to local governments, we apply such framework at the local level. The ultimate goal is to develop appropriate tools for decentralized planning support. To this end, the study first implements a methodology for primary data collection, which combines the household and the waterpoint as information sources. In doing so, we provide a complete picture of the context in which domestic WASH services are delivered. Second, the collected data are analysed to underline the emerging development challenges. The use of simple planning indicators serves as the basis to i) reveal which areas require policy attention, and to ii) identify the neediest. Third, a classification process is proposed to prioritize among various populations. Three different case studies from East and Southern African countries are presented. Results indicate that accurate and comprehensive data, if adequately exploited through simple instruments, may be the basis of effective targeting and prioritization, which are central to sector planning. The application of the proposed framework in the real world, however, is to a certain extent elusive; and we point out to conclude two specific challenges that remain unaddressed, namely the upgrade of existing decisionmaking processes to enhance transparency and inclusiveness, and the development of data updating mechanisms.

Keywords: household survey; local planning; planning indices; Sub-Saharan Africa; water point mapping 
Abbreviations

CLTS Community-led total sanitation

$\mathrm{Cl} \quad$ Confidence Interval

FIWP Functional improved waterpoint

$\mathrm{HH} \quad$ Household

HW Handwashing

ISF Improved sanitation facility

IWP Improved waterpoint

MICS Multiple Indicator Cluster Survey

NGO Non-governmental organization

OD Open defecation

UNICEF United Nations International Children's Emergency Fund

UWP Unimproved waterpoint

WASH Water, Sanitation and Hygiene

WP Waterpoint

WPM Water Point Mapping 


\section{INTRODUCTION}

Diseases related to insufficient and unsafe drinking water, unimproved sanitation and poor hygiene education are common causes of illness and death (Cairncross et al., 2010; Esrey et al., 1991). In addition, the benefits of improved services provision are central to the cycle of disease and poverty, but they are rarely enjoyed by the most vulnerable (Cortinovis et al., 1993). Up to date, progress in ensuring access to these basic services has remained elusive in much of the developing world, where recent estimates show that a vast proportion of people still lack a simple pit latrine and a source of safe drinking water (Joint Monitoring Programme, 2014).

In last decades, the sector has been experiencing a decentralization of responsibilities, where decision-making moves to local administrative units and decentralized bodies assume some political autonomy. The underlying rationale for this process is that decentralized governments have an informational advantage over the central government with regard to local needs and priorities, for which reason they are assumed to supply services in accordance with demand, allocate resources more equitably, and ultimately conceive and implement policies with a focus on poverty reduction (Steiner, 2007). Decentralization is also supposed to decrease corruption, as well as increase public participation and the accountability of public officials (Steiner, 2007). These beliefs are, however, naïve, and effective implementation of these processes remains elusive. The links between decentralization and pro-poor planning are at best ambiguous, and achieved outputs vary between countries (Blair, 2000; Crook, 2003; Devas and Grant, 2003; Jiménez and Pérez Foguet, 2011; Steiner, 2007). This problem is aggravated in rural settings by a general lack of reliable information systems capable of describing the situation at the grassroots level.

For decentralisation to work effectively there is indeed a need of selfgovernments that are accountable for the performance of service delivery. This requires, amongst others, innovative tools for bringing about a more equitable allocation of resources (Jiménez and Pérez Foguet, 2010a), combined with adequate accountability mechanisms (Blair, 2000; Devas and Grant, 2003). Both targeting and accountability are central to pro-poor planning, and depend on the availability of accessible information to i) identify those sector areas and population groups most in need, ii) improve transparency in budget allocation procedures, and iii) measure progress. Similarly, civil society wants objective data which testify to the use of limited resources. Such information is often missing in many countries, particularly in rural areas, but even when it is available, there is no guarantee that it is adequately exploited for planning and 
monitoring purposes. Political will and management-related capacities are further requirements that hinder informed decision-making.

In an effort to address the first two shortcomings cited above, i.e. lack of reliable data and inadequate mechanisms for pro-poor planning in decentralized contexts, the aim of this study is to outline a monitoring framework to compile, analyse, interpret and disseminate water, sanitation and hygiene (WASH) information. Issues covered range from improving the availability of reliable information, to improving access to information, and to encouraging the use of this information in decision-making processes. It may be conceptualised as a stepped approach. The first step is to apply a survey methodology to collect and make available consistent field data. It takes the Water Point Mapping (WPM) as starting point to comprehensively record all improved water sources at the area of intervention. This information is combined with data provided from a household-based survey, in which a representative sample of households is selected to assess sanitation and hygiene habits. The second step is to analyse the data to highlight the emerging development challenges and provide evidences that help determine what gets done, and where. To do this, a set of simple planning indicators serve as the basis to rank population groups and reveal which areas may be most in need of further investment. The third step is to propose a prioritization process to help translate previous development potentials into the formulation of planning strategies. Based on simple statistics, a criterion of non-overlapping between the confidence intervals $(\mathrm{Cl})$ of the estimates is applied to define prioritization groups.

This paper documents three different case studies in East and Southern Africa, namely the district of Kibondo (Tanzania, 2010), the district of Homa Bay (Kenya, 2011) and the municipality of Manhiça (Mozambique, 2012). It is organized as follows. The next section outlines the methodology employed in this study for data collection, and the approach adopted for planning is presented. Mechanisms for prioritization and targeting purposes are introduced. Afterwards, the situation of WASH issues in the area of intervention is examined; and on the basis of this analysis, priorities are identified and proposals to overcome major development challenges are articulated. Main findings are discussed. The paper concludes with a discussion of policy relevance of the proposed monitoring framework.

\section{METHODOLOGY}

In terms of method, study's implementation is three-fold. A comprehensive assessment of WASH issues at the dwelling is first carried out through the implementation of survey methodology that combines the household and the 
waterpoint as information sources (Giné Garriga et al., 2013a). Second, a short set of easy-to-use planning tools are developed. It takes the water-related indices developed by Jiménez and Pérez Foguet as starting point (2010a), and then defines new indices to cover the issues of household sanitation and domestic hygiene. To improve decision-making, specifically for prioritization and targeting support, a classification process is finally proposed based on simple statistics of the estimates produced.

It is well known, however, that the uptake for such instruments by decisionmakers is, at best, challenging, and they commonly do without them (WaterAid, 2010). Limited capacities of recipient institutional bodies, inadequate sectorrelated institutional framework, lack of data updating mechanisms, or poor interaction between academics and practitioners during the design phase are common reasons that hamper an adequate appropriation and continued use of the developed tools. Given these circumstances, this study first considers the local authority as the principal stakeholder, and specifically engages in various stages of the process with those government bodies with competences in WASH. The involvement of local officers in data collection campaigns promotes and facilitates the link between field workers and the structures at community level. They also help reduce the risk of overlooking certain parts of the visited villages. And being the principal end-user of the outcomes produced, their involvement promotes sense of ownership over the process, as prerequisite for incorporating the data into decision-making. Similarly, a consultative approach with local policymakers is adopted for indices definition and the design of the threshold criteria. Otherwise, the analysis of the data often goes beyond the means and capacities of the local technicians, who are unable to capture the main policy messages underlying the data. Second, all planning instruments are applied at the administrative scale in which decisions are made, and principles guiding their design include simplicity, functionality and transparency. Third, the proposed tools and methods are not only user-friendly (easy to implement, easy to understand), but presented in a way that provides clear messages and communicates a picture to decision-makers and potential beneficiaries quickly and accurately. As further discussed below, these measures are necessary and proved helpful, but probably become insufficient to effectively address by themselves the various challenges cited before.

\subsection{Data collection}

The approach adopted for data collection combines a waterpoint mapping with a household survey, and it is presented in detail in a companion article (Giné Garriga et al., 2013a). 
In brief, the mapping methodology can be described as an "exercise whereby the geographical positions of all improved waterpoints ${ }^{1}$ in an area are gathered in addition to management and technical data" (WaterAid and ODI, 2005). It involves the presentation of this information in a spatial context, which enables a rapid visualization of the distribution and status of water supplies. By linking these point data with demographic information, WPM objectively demonstrates who is and is not served; thus becoming a valuable analysis and planning tool for decentralized governments. Specifically, the mapping does not refer to a fixed set of indicators, and two additional actions are suggested in this regard: i) biological testing of water quality; and ii) the inclusion of unimproved sources.

Besides to the mapping, a survey is conducted to observe sanitation status and assess hygienic habit, in which the household $(\mathrm{HH})$ is taken as the basic sampling unit. The design and selection of the sample draws on the Multiple Indicator Cluster Survey (MICS), i.e a methodology developed by UNICEF to collect social data (United Nations Children's Fund, 2006). The study population is stratified into a number of small mutually exclusive and exhaustive groups (strata), so that members of one group cannot be simultaneously included in another group. However, since mapping of waterpoints obliges to cover the whole area of intervention, main difference when sampling is that a sample of households is selected in this exercise from each stratum (stratified sampling), rather than selecting a reduced number of strata, from which a subsample of households is identified (cluster sampling). In doing so, the risk of homogeneity within the strata remains relatively low, thus reducing the need for applying any correction factor in sample size determination, i.e. the design effect ${ }^{2}$. A design effect " $D$ " of 1 is typically employed in stratified random sampling, though tenfold or even higher values are not uncommon values in WASH cluster-based studies (Bostoen, 2002; Giné Garriga et al., 2013b; Kish, 1980; United Nations Children's Fund, 2006).

In all, key features of the methodology include (Giné Garriga et al., 2013a): i) an exhaustive identification of enumeration areas (administrative subunits as locations, villages, communities, etc.); ii) audit in each enumeration area of all improved water points accessed for domestic purposes; and iii) random selection of a sample of households that is representative at the local administrative level (e.g. district, municipality, etc.) and below. The proposed framework thus makes use of two widely accepted methods, i.e. the waterpoint mapping and the household survey, to collect WASH data in a cost-effective manner. Table 1 summarizes main methodological issues considered in each case study. 
Table 1 Key methodological features of the approach adopted for data collection in each case study. Source: Giné Garriga et al., 2013a

\begin{tabular}{|c|c|c|c|c|}
\hline \multirow[t]{2}{*}{ Case Study } & \multirow{2}{*}{$\begin{array}{l}\text { Adm. Division } \\
\text { Unit (Subunits) }\end{array}$} & \multicolumn{2}{|c|}{ Data collection } & \multirow[t]{2}{*}{ Key features } \\
\hline & & No. WPS ${ }^{a}$ & No. $H H$ & \\
\hline \multirow[t]{3}{*}{$\begin{array}{l}\text { Kibondo, } \\
\text { Tanzania }\end{array}$} & $\begin{array}{c}\text { District } \\
\text { (20 Wards) }\end{array}$ & 986 IWPS & 3.656 & $\begin{array}{l}\text { - Sampling Plan (at ward level): } \alpha=0.05 ; \mathrm{D}=2 ; \mathrm{d}= \pm 0.10 ; \mathrm{n}(\min )= \\
\text { 192. }\end{array}$ \\
\hline & & & & $\begin{array}{l}\text { - The WP audit included } 38 \text { questions ( } 30 \text { minutes per WP) }+1 \text { water } \\
\text { quality test. } \mathrm{HH} \text { checklist included } 18 \text { questions related to sanitation } \\
\text { and domestic hygiene issues ( } 10 \text { minutes per } \mathrm{HH} \text { ). }\end{array}$ \\
\hline & & & & $\begin{array}{l}\text { - The field team included one staff from Spanish NGO, } 1 \text { technician } \\
\text { from District Water Department, two staff from a consultancy firm and } \\
\text { two people from each visited village. Field work was completed in } 42 \\
\text { days. }\end{array}$ \\
\hline \multirow{5}{*}{$\begin{array}{l}\text { Homa Bay, } \\
\text { Kenya }\end{array}$} & District & & 1.157 & - Sampling Plan (at division level): $\alpha=0.05 ; \mathrm{D}=2 ; \mathrm{d}= \pm 0.10 ; \mathrm{n}(\mathrm{min})=$ \\
\hline & (5 divisions) & 187 IWPs & & 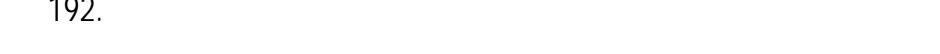 \\
\hline & & and 68 & & - Unimproved WPs were audited in only 3 out of 5 divisions. The WP \\
\hline & & UWPS & & $\begin{array}{l}\text { audit included } 38 \text { questions ( } 30 \text { minutes per WP) }+1 \text { water quality } \\
\text { test. } \mathrm{HH} \text { checklist included } 65 \text { questions related to water, sanitation } \\
\text { and domestic hygiene issues ( } 35 \text { minutes per } \mathrm{HH} \text { ). }\end{array}$ \\
\hline & & & & $\begin{array}{l}\text { - The field team included tree staff from UPC (1 fully involved), } 1 \\
\text { technician from the District Water Department (partially involved), } 1 \\
\text { technician from the District Public Health Department (partially } \\
\text { involved), } 8 \text { staff from a consultancy firm, and one people from each } \\
\text { visited community. Field work was completed in } 33 \text { days. }\end{array}$ \\
\hline \multirow{3}{*}{$\begin{array}{l}\text { Manhiça, } \\
\text { Mozambique }\end{array}$} & Municipality & 228 & 1.229 & - Sampling Plan (bairro level): $\alpha=0.05 ; \mathrm{D}=2 ; \mathrm{d}= \pm 0.15 ; \mathrm{n}(\mathrm{min})=86$ \\
\hline & (18 bairros) & $\begin{array}{l}224 \text { IWPS } \\
\text { and } 4 \\
\text { UWPs }\end{array}$ & & $\begin{array}{l}\text { - Audit of improved and unimproved WPs. The WP audit included } 41 \\
\text { questions ( } 30 \text { minutes per WP) + } 1 \text { water quality test. HH checklist } \\
\text { included } 82 \text { questions related to water, sanitation and domestic } \\
\text { hygiene issues ( } 45 \text { minutes per } \mathrm{HH} \text { ) }\end{array}$ \\
\hline & & & & $\begin{array}{l}\text { - The field team included three staff from UPC (1 fully involved), } 3 \\
\text { technicians from the Vereação para Urbanização, Construção, Água e } \\
\text { Saneamento (partially involved), } 14 \text { staff from a consultancy firm and } 1 \\
\text { people from each visited village. Field work was completed in } 29 \text { days. }\end{array}$ \\
\hline
\end{tabular}

Note: a) Type of waterpoints includes IWP for Improved waterpoint and UWP for unimproved waterpoint. b) $\alpha$ is the confidence level, $D$ is the design effect, and $d$ is the required precision on either side of the measurement.

\subsection{Design of planning tools}

To effectively base decision-making on available and sector-specific data, two elements are necessary (Grosh, 1997): the data must be analysed to produce outcomes that are relevant to the policy question, and the analysis must be disseminated and transmitted to policymakers. In terms of poverty reduction, successful planning also relies on selecting beneficiaries based on real hardship. The ultimate goal of local level planning is thus to target the neediest and promote equity-oriented prioritization mechanisms. 
With this in mind, this study analyses baseline data as the starting point for planning. The analysis provides a complete picture of how well the sector is faring, while enables comprehensive understanding of key sector-related constraints to development. It is thus essential that the monitoring framework looks beyond data on service coverage and integrate a broader view of service delivery (Giné Garriga and Pérez Foguet, 2013; Jiménez and Pérez Foguet, 2012; Joint Monitoring Programme, 2011). Amongst others, information about institutional, financial, management and environmental issues should be adequately addressed. However, exhaustiveness needs to be balanced with simplicity. A reduced set of indices are defined herein on the basis of simple planning criteria (Jiménez and Pérez Foguet, 2010a). For each index, one ranking is produced and transposed into one league table to denote priorities. A different threshold limit is set per list for this purpose; and whenever two administrative subunits score same index value in one ranking, the most populated one is first positioned to maximize number of beneficiaries. To show at a glance both index values and priorities, different maps are developed, which enable a quick identification of key focus areas. Finally, each priority list is related with specific remedial actions to be accomplished by the local government, ultimately translating development challenges into beneficial development activities. A proposed list of indices is summarized in Table 2.

\subsection{Definition of priorities to support decision-making}

When defining priorities, a key issue is to guarantee reliability of the outcomes produced and thus avoid decisions based on false or misleading assumptions.

The data collected at the waterpoint is exhaustive -all waterpoints are included in the mapping exercise- and thus can be meaningfully analysed at different geographical scales. This offers advantages over household data in terms of statistical precision and accuracy. In consequence, water-related indices are computed on WPM data. In this study, the location (Kenya), village (Tanzania) and bairro (Mozambique) scale has been opted for since they embody the last level of the institutional ladder in which planning decisions are made. 


\section{INDICES RELATED TO THE QUALITY OF THE SERVICE}

\section{Seasonality Index \\ $\%$ of FIWP that are year-round}

Water Quality Index

\%of FIWP with acceptable bacteriological quality

\section{INDICES RELATED TO SANITATION SERVICE}

Coverage Index $\%$ of covered households by improved sanitation facilities (ISF)

Open Defecation

Index

$\%$ of households that practice open defecation (OD)

\section{INDICES RELATED TO HYGIENE}

Latrine Sanitary

Conditions Index

$\%$ of latrines that are maintained in adequate sanitary conditions. Risky conditions might prevent an adequate use

Handwashing index $\quad \%$ of adults with appropriate handwashing (HW) knowledge

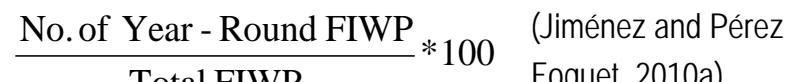 Total FIWP Foguet, 2010a)}

\section{$\frac{\text { No. of Safe FIWP }}{\text { Total FIWP }} * 100$}

(Jiménez and Pérez Foguet, 2010a)

\section{$\frac{\text { No. of HH with ISF }}{\text { Total HH }}$}

No. of $\mathrm{HH}$ practicing OD Total $\mathrm{HH}$
(Joint Monitoring

Programme, 2008

2006)

(Joint Monitoring

Programme, 2008;

WaterAid, 2009)

No. of Sanitary Latrines Total Latrines

No. of Adults with HW Total Adults
Actions to increase reliability of the source

(catchment's protection, regulation of different uses) and/or finding of additional sources

Actions to improve quality of water: catchment's protection, protection of WP, water treatment, etc. If salinity is high and becomes dangerous, check other alternative sources WP

Construction of new facilities

Community-led Total Sanitation 
On the other hand, it is noteworthy that household estimates are inferred from a representative sample taken from the overall population. Therefore, some basic statistics are needed to analyse the results. To prioritize among various populations in relation to a given variable, a common approach is to consider the proportion $p$ of households verifying such variable with its respective confidence interval "Cl" $\left(p_{L}, p_{U}\right)$. However, at local level with reduced populations -the analysis of sanitation and hygiene-related indices has been performed at division (Kenya), ward (Tanzania) and bairro (Mozambique) level-, precision of estimates is often sacrificed due to sampling issues. Since large sample sizes would hinder in practice the implementation of local surveys, relative large lengths of confidence intervals are typically obtained. This presents a drawback from the viewpoint of interpretability. Small area estimates (Ghosh and Rao, 1994; Rao, 2003) may be used to improve precision but only to a limited extent. In these contexts, the abovementioned approach is often underused or misused.

In this study, we employ a simple criterion to assign the estimates $p$ to a specific category within a finite set of sorted options. Let us consider the set of sorted categories covering the interval $C=[0,1]$ defined as $\bigcup_{i=1, \ldots, m} C_{i}=C$, with null intersection between them. For instance, the intervals $C_{i}=\left[l_{i}, u_{i}\right)$, with $l_{1}=0$, including left boundary but not the right one, for $i=1, \ldots, m-1$, and the last interval $C_{m}=\left[l_{m-1}, 1\right]$, which includes both boundaries. Each category is characterized by its limit values $l_{i}$ and $u_{i}$. To define the set of categories, we analyse the potential overlapping between the confidence interval $(\mathrm{Cl})$ of estimates from one category with the $\mathrm{Cl}$ of the limit values of the other categories. Specifically, the criterion to accept the set of categories is that if an estimate lies in $C_{i}$, there is no reasonable chance for the real value to belong neither to $C_{i-2}$ nor to $C_{i+2}$. Formally, the hypothesis test of the difference between proportions belonging to alternate categories being equal to zero is rejected in all cases.

The simplest and usually used categorization, the "uniform" one with interval lengths given by the imposed precision, $h_{i}=u_{i}-l_{i}=h=2 /$ int $(1 / d)$, verifies the previous criterion. And from a practical perspective, it entails that for a given $d=0.05(h=0.1)$, ten categories of $p$ are justified for $C=[0,1]$. However, three categories are defined for $d=0.16(h=0.33)$, and only two for larger values of $d$. Instead of "a priori" and "uniform" categorization, the categorization may be defined on the basis of achieved interval estimates, by imposing the nonoverlapping principle described above. This can be easily applied by comparing the $\mathrm{Cl}$ of a given estimate $p$ lying in $C_{i}$ with those of limit estimates located in $C_{i-2}$ and $C_{i+2}$; specifically, whether $p_{U, C_{i}}$ is lower than $p_{L, C_{i+2}}$, and whether $p_{L, C_{i}}$ is 
larger than $p_{U, C_{i-2}}$. If both conditions are confirmed for all estimates, the set of categories $C_{i}$ may be considered adequate to discriminate proportions.

\subsection{Study Area}

Three different East African settings have been purposively selected as initial case studies to test the applicability and validity of the proposed methodology. Kibondo is one of the 4 districts of the Kigoma Region of Tanzania. It is administratively divided into 20 wards. According to the 2002 National Census, the population is estimated at 414,764 . The rural District of Homa Bay is located in Nyanza Province, in western Kenya. The total area is $1,169.9 \mathrm{Km}^{2}$ and the population is estimated at 366,620 (2009 census). Administratively, the district is divided into five divisions, and the divisions are further sub-divided into 25 locations and 63 sub-locations. The Municipality of Manhiça is located in Manhiça District - Maputo Province, in southern Mozambique. It has 19 bairros and covers a rough area of $250 \mathrm{~km}^{2}$. According to the local estimates, the population roughly totals 61,000 distributed in peri-urban and rural contexts.

\section{RESULTS AND DISCUSSION}

This section presents situational analysis of WASH issues. To do this, we make use of the indices listed above. However, the aim is not to provide an in-depth assessment of those regional sectors and geographic areas that require urgent policy attention, it is more about showing an improved approach for local planning. In other words, the focus is not on a comparative analysis of WASHrelated challenges in the selected study areas, but rather on testing the validity of the indices as targeting and prioritization tools. To support formulation of tailored interventions, the discussion groups planning indices and related remedial actions based on their nature, i.e. i) water supply, and ii) sanitation and hygiene.

\subsection{Water Supply Planning}

Access to water is determined primarily by distance to the source, since quantity that will be collected will probably not reach a minimum requirement for domestic purposes where fetching takes more than 30 minutes (Cairncross and Feachem, 1993; Pickering and Davis, 2012). Other aspects which may hinder accessibility are seasonality, quality and affordability (Howard and Bartram, 2003; Jiménez and Pérez Foguet, 2012). Therefore, water coverage can be categorised in terms of service level, by considering a combination of 
aforementioned requirements (Howard and Bartram, 2003; Kayser et al., 2013). However, where optimal access is provided but the supply is not functional, other unimproved sources might become a temporary solution (Hunter et al., 2009). This draws attention to the issue of service management.

Access to water. The common method to estimate coverage is based on standard assumption on the number of users per improved water source, i.e. the man:source ratio, which for instance in Tanzania stands at 250 people per public tap (Government of United Republic of Tanzania, 2006). First index thus depicts the number and geographic distribution of waterpoints in terms of the population living in the area, and thus identifies those administrative subunits most in need of new waterpoints' construction. It is gleaned from the coverage map (Figure 1) that current availability of improved sources in Kibondo District is not only poor, i.e. half of the population has no access to improved waterpoints, but marked regional disparities also hamper equity issues. There are some villages with no access to improved waterpoints (red coloured in the map), while in 33 villages the man:source ratio is lower than the policy target (coloured in dark green).

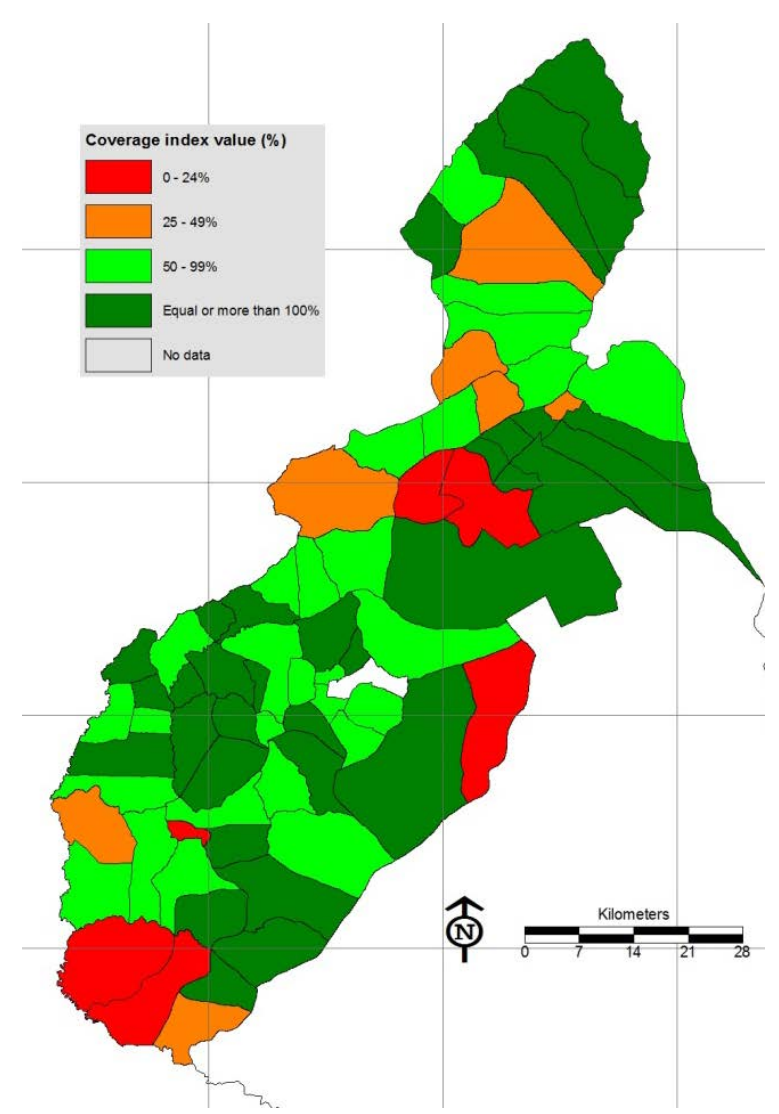

Figure 1 Coverage Index - Water Supply (Kibondo District, Tanzania)

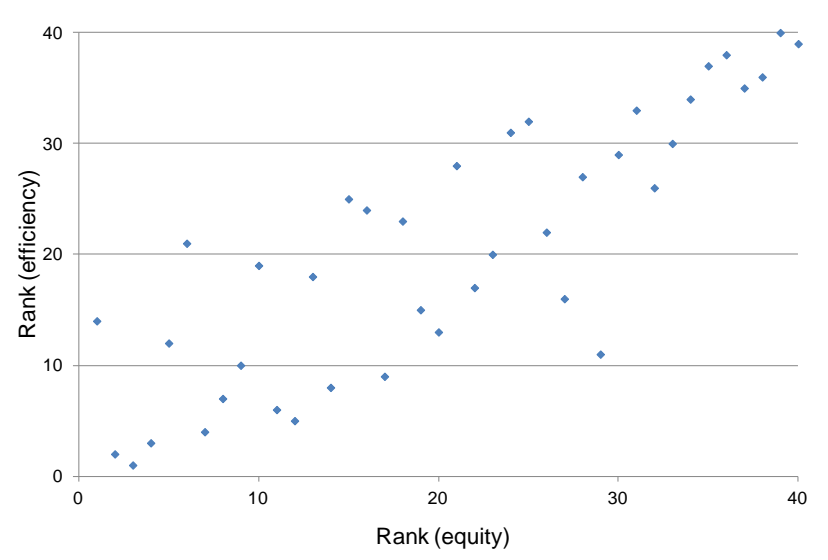

Figure 2 Coverage Ranks (equity versus efficiency) 
Table 3 Priority List for Construction of New IWPs (Kibondo District, Tanzania)

\begin{tabular}{|c|c|c|c|c|c|c|c|}
\hline $\begin{array}{c}\text { Rank } \\
\text { (equity) }\end{array}$ & $\begin{array}{c}\text { Rank } \\
\text { (efficiency) }\end{array}$ & Ward & Village a & $\begin{array}{l}\text { Estimated } \\
\text { Population }\end{array}$ & $\begin{array}{l}\text { Coverage } \\
\text { Index }{ }^{b}\end{array}$ & $\begin{array}{l}\text { Unserved } \\
\text { Population b }\end{array}$ & $\begin{array}{c}\text { Required No. } \\
\text { New IWP b }\end{array}$ \\
\hline 1 & 14 & Rugongwe & Magarama & 1717 & $0,0 \%$ & 1717 & 7 \\
\hline 2 & 2 & Kasanda & Chilambo & 49398 & $2,0 \%$ & 48398 & 194 \\
\hline 3 & 1 & Murungu & Kumbanga & 52541 & $4,3 \%$ & 50291 & 202 \\
\hline 4 & 3 & Kasanda & Kasanda & 49398 & $9,6 \%$ & 44648 & 179 \\
\hline 5 & 12 & Busagara & Kumkuyu & 2118 & $11,8 \%$ & 1868 & 8 \\
\hline 6 & 21 & Kumsenga & Kigina & 1717 & $14,6 \%$ & 1467 & 6 \\
\hline 7 & 4 & Rugongwe & Nyankwi & 7073 & $25,0 \%$ & 5323 & 22 \\
\hline 8 & 7 & Kumsenga & Kumsenga & 4240 & $41,3 \%$ & 2490 & 10 \\
\hline 9 & 10 & Kasuga & Nyakayenzi & 3587 & $41,8 \%$ & 2087 & 9 \\
\hline \multirow[t]{2}{*}{10} & 19 & Kakonko & Mbizi & 2809 & $44,5 \%$ & 1559 & 7 \\
\hline & & & $\ldots$ & & & & \\
\hline 32 & 26 & Busagara & Kasaka & 5661 & $79,5 \%$ & 1161 & 5 \\
\hline 33 & 30 & Kumsenga & Kibuye & 4659 & $80,5 \%$ & 909 & 4 \\
\hline 34 & 34 & Misezero & Kumuhama & 3397 & $81,0 \%$ & 647 & 3 \\
\hline \multirow[t]{2}{*}{35} & 37 & Kibondo Mjini & Kumwambu & 2666 & $84,4 \%$ & 416 & 2 \\
\hline & & & $\ldots$ & & & & \\
\hline 40 & 39 & Nyabibuye & Nyabibuye & 3520 & $92,3 \%$ & 270 & 2 \\
\hline 41 & 41 & Mugunzu & Nyagwijima & 4287 & $99,1 \%$ & 37 & 1 \\
\hline 42 & 42 & Kitahana & Rusohoko & 4464 & $100,8 \%$ & 0 & 0 \\
\hline 43 & 43 & Mugunzu & Mugunzu & 2177 & $103,4 \%$ & 0 & 0 \\
\hline
\end{tabular}

Note: a) In red colour, locations with risky coverage (<25\%). In orange, locations with poor coverage (25 - 50\%). In green, locations with acceptable coverage (>50\%); b) In Tanzania, the man:source ratio stands at 250 people per public tap.

To tackle water shortages, various approaches may be adopted when defining the list of priorities. In terms of regional equity, the goal would be to reach a minimum coverage threshold in every administrative unit, as commonly established in national policies. For example, the rural WASH initiative launched by the World Bank in Tanzania aims to increase coverage nationwide and reach at least $80 \%$ in all districts by 2025 (Government of United Republic of Tanzania, 2006). The focus in these cases should be on underserved areas, and for instance target in first place the villages included in the poorest and least-served quartile. Based on an efficiency criterion, however, those 
administrative units with highest number of potential beneficiaries would be first targeted, regardless of coverage. A combination of both criteria is also feasible, but this would result in a complex indicator and has accordingly been dismissed. From Table 3, it can be seen that one different ranking is produced depending on each of abovementioned criteria, showing both ranks poor correlation (Figure 2). The equity criterion has been opted for in this planning exercise. It emphasizes those underserved locations with highest man:source ratios, where vulnerability is higher due to total absence of improved supplies (Jiménez and Pérez Foguet, 2010a).

Functionality of waterpoints. This second group of indices aims to analyse those key aspects that enable a water scheme to remain operational over a long period of time, and therefore identify the facilities in need of soft-based support. A water supply can be interrupted because of functionality / management reasons or seasonality issues. Regardless the cause, lack of continuity may lead to prolonged periods without supply, obliging households to search for alternative sources, often of inferior availability and poorer quality. Service continuity is therefore essential in benefiting health.

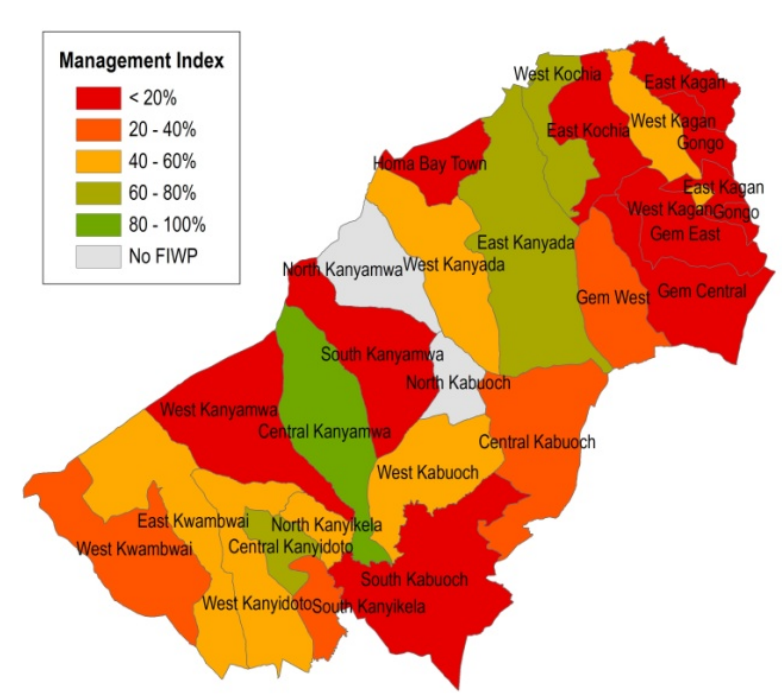

Figure 3 Management Index (Homa Bay District, Kenya)

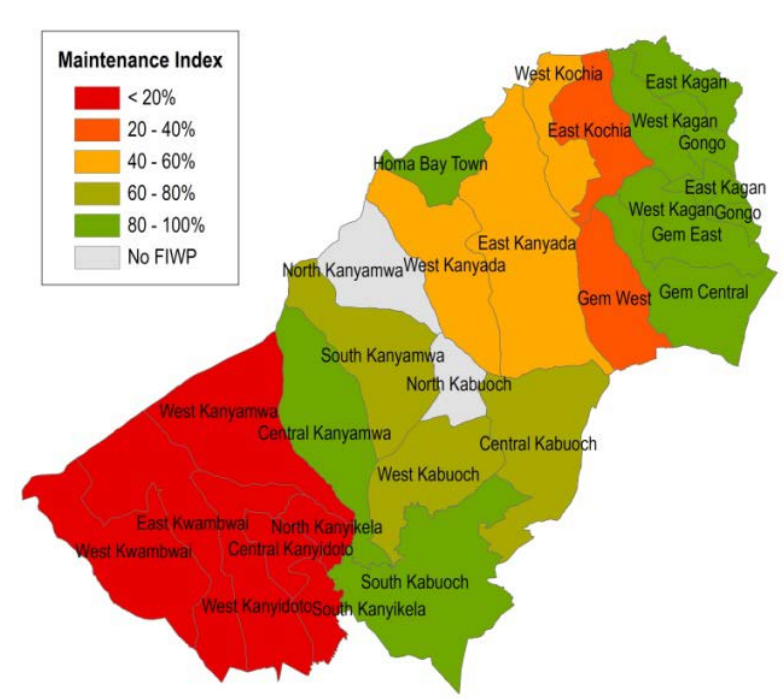

Figure 4 Maintenance Index (Homa Bay District, Kenya)

Functionality is defined in this exercise as the percentage of improved sources that are functional at the time of spot-check. In those locations with lowest index values, the strategy should consider the rehabilitation of non-operational waterpoints as an alternative to the construction of new infrastructure. In parallel, and to reduce recidivism, management and operation capacity gaps should be properly identified to promote long-term sustainability. More 
specifically, soft-based support initiatives to water user entities emerge as efficient solutions, such as promotion of their legal registration, financial and technical support to build up capacities of managers and technicians, etc. To further the analysis on functionality issues, two additional indicators are analysed, one related to management and another one related to maintenance. For service management, a financial criterion has been employed, and the proportion of functional waterpoints with declared incomes and expenditures has been taken as proxy (Jiménez and Perez-Foguet, 2011). From the map in Figure 3 , it can be seen that a considerable number of water entities do not have an appropriate payment system in place, therefore hindering their ability to meet ongoing O\&M costs. To draw attention to maintenance needs, a complementary index estimates the percentage of waterpoints that are operational and have easy access to a reliable supply chain and to qualified technicians. It is gleaned from Figure 4 that such access remains elusive in some locations, where neither technical skills nor a reliable supply chain are locally available.

Seasonality of water sources. Service continuity also depends on seasonality issues; and where seasonality of water resources is high, people often need to search for alternative sources during dry season. This planning indicator estimates the percentage of functional waterpoints that are year-round (not seasonal), where seasonality is defined as more than one month of water shortage. It can be observed from the map (Figure 5) that the majority of supplies (84\%) are year-round. Therefore, and though this figure slightly varies across the locations, seasonality is not an issue in Homa Bay. Remedial actions where seasonality is high would include catchments' protection, improvement of water storage, research on water technologies in dry areas, etc.

Water quality. Water quality surveillance should be a required activity in any monitoring framework, since the relevance of accessing safe water for disease prevention is widely recognized (Esrey et al., 1991; Fewtrell et al., 2005). Water safety is herein understood as non-presence of faecal coliforms; i.e. the planning index informs about the proportion of operational sources with a faecal coliform count of more than zero. It can be seen in the map in Figure 6 that a considerable number of water sources (30.8\%) are affected by microbiological contamination, which emphasizes the fact that improved waterpoints do not always supply safe water. Again, regional differences are pronounced. And interestingly, the map depicts that those areas showing faecal contamination are to certain extent geographically clustered.

Water sources may be contaminated because of poor sanitary protection measures due to inadequate design, sitting, construction or operation and 
maintenance. Therefore, in those prioritized villages, interventions are required in the form of engineering interventions to improve the protection or the environmental hygiene around the source; or actions to promote good community management. The design of abovementioned activities could be supported by regular sanitary inspections (Howard, 2002).

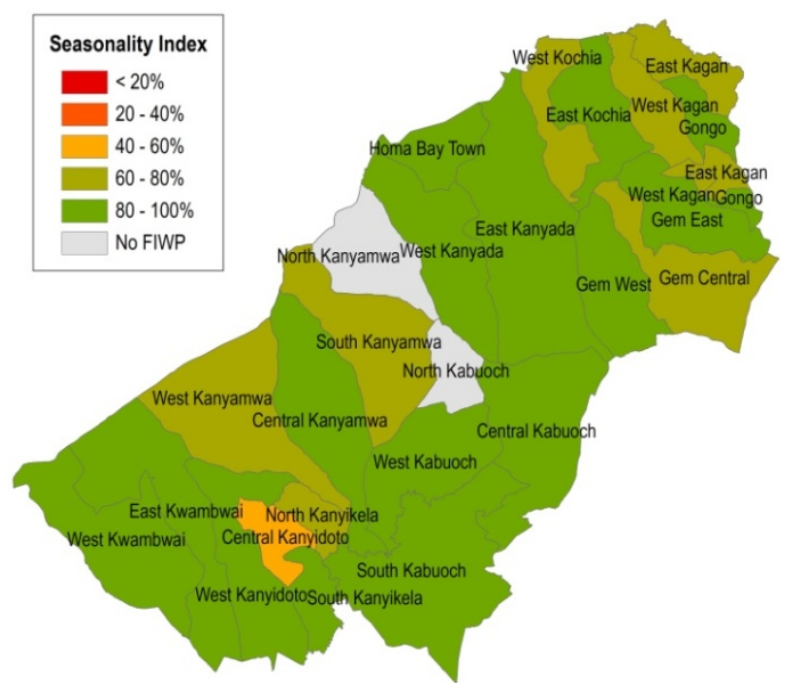

Figure 5 Seasonality Index (Homa Bay District, Kenya)

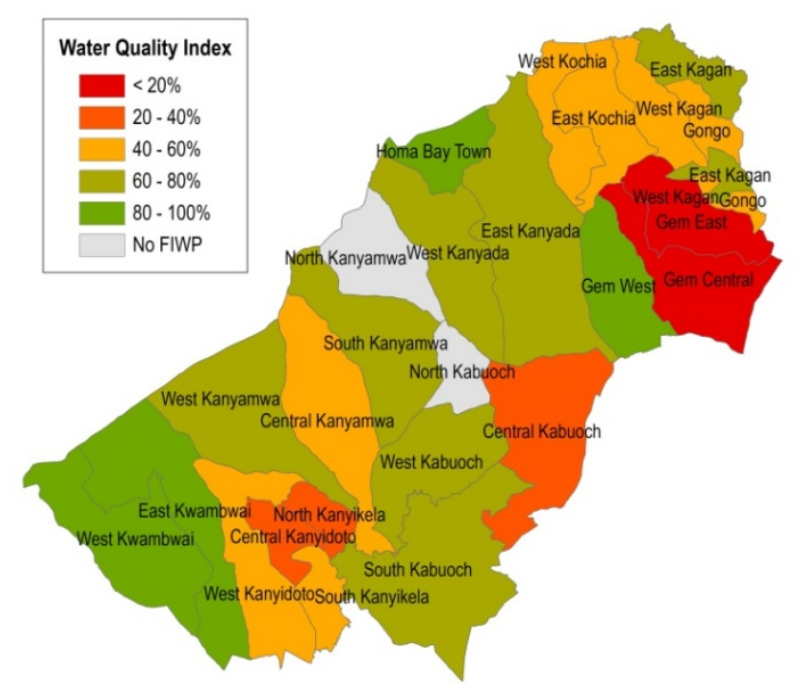

Figure 6 Water Quality Index (Homa Bay District, Kenya)

\subsection{Sanitation and Hygiene Planning}

Sanitation monitoring often focus on the "hardware" -for example, number of latrines or sewerage systems- whilst neglecting the "software" -hygiene knowledge and behaviours- (Dreibelbis et al., 2013). However, beyond access to infrastructure, it is well known that lack of latrine maintenance results in a focus for the transmission of diseases, apart from hindering a continued use (Scott et al., 2003). Personal hygiene (principally hand-washing), on the other hand, is the only protective barrier which can effectively block all faecal-oral routes of disease transmission (sanitation hardware only prevents faeces contaminating the environment; transmission via fingers is also common), and research has demonstrated that increased hand-washing significantly diminishes the incidence of diarrhoea (Curtis and Cairncross, 2003; Luby et al., 2005). For planning purposes, sanitation monitoring needs to be defined in a broad and more holistic sense (Breslin, 2010) to include, amongst others, hygiene issues. The previous challenges may be translated into respective planning indices.

Use of sanitation. As mentioned above, a technology-based approach is adopted when estimating the sanitation figures. Specifically, coverage is 
presented as a four-step ladder ${ }^{3}$ that distinguishes between open defecation, unimproved, shared, and improved sanitation (Joint Monitoring Programme, 2008).

Two complementary indices are designed to assess the "hardware" component at the dwelling: i) use of improved sanitation, and ii) practice of open defecation. As visualized in the maps (Figures 7 and 8), the situation in the municipality of Manhiça is far from being adequate: use of improved infrastructure stands at $26.4 \%$, and $14.2 \%$ of total population has no access to sanitation at all. In addition, disparities exist by bairros, and for instance population in Manhiça Sede (coverage of $58,7 \%$ ) is nine times as likely to use an improved sanitation facility as the population in Mitilene (6.7\%). On the other hand, a large majority of households defecate in the open in Ribjene (61.3\%), while in other bairros this practice has been almost eliminated.

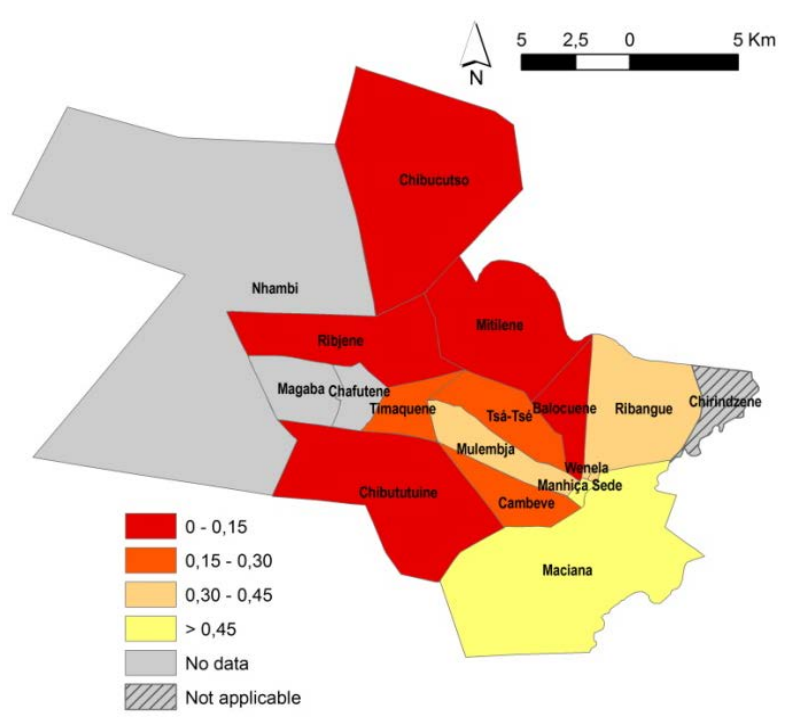

Figure 7 Coverage Index - Sanitation (Manhiça, Mozambique)

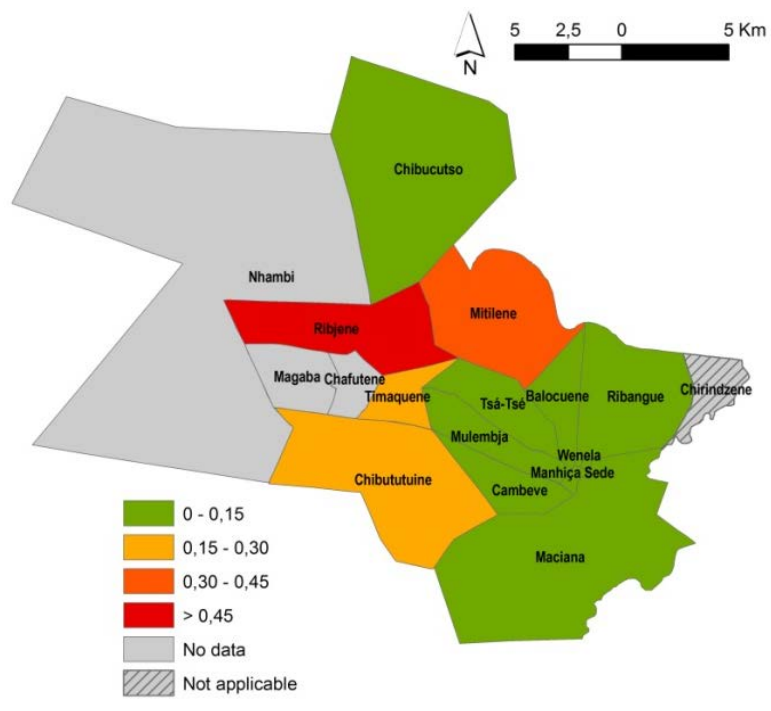

Figure 8 Open Defecation Index (Manhiça, Mozambique)

From the viewpoint of decision-making, the classification process described above is employed for prioritization purposes. When the focus is on the availability of sanitation infrastructure, Table 4 shows that two different groups are obtained by applying the uniform categorization. Given $d=0.15(h=0.33)$, the cut off values to set up the categories are 0,33 and 0,66 . In contrast, four categories are defined by imposing a posteriori the non-overlapping principle. It is verified, for instance, that $\mathrm{i})\left(\mathrm{p}_{\mathrm{u}, \mathrm{i}}\right)$ Chibututuine is lower than $\left(\mathrm{p}_{\mathrm{l}, \mathrm{i}}\right)_{\text {Matadouro }}(0,208<$ $0,229)$; and $\mathrm{ii})\left(\mathrm{p}_{\mathrm{u}, \mathrm{i}}\right)$ Timaquene is lower than $\left(\mathrm{p}_{\mathrm{l}, \mathrm{i}}\right)$ Maciana $(0,344<0,450)$. Similar planning outcomes are observed in Table 5 , which presents the ranks related to the practice of open defecation. The uniform categorization produces the same two groups, while four categories are defined through the application of the non- 
overlapping criterion: $\mathrm{i})\left(\mathrm{p}_{\mathrm{u}, \mathrm{i}}\right)$ Mulembja is lower than $\left(\mathrm{p}_{\mathrm{l}, \mathrm{i}}\right)$ Matadouro $(0,149<0,240)$;

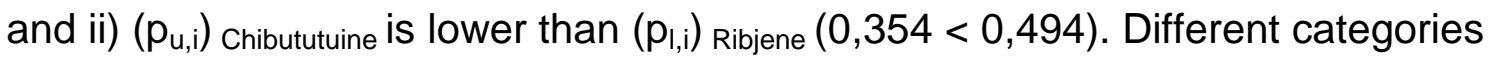
may be defined for different purposes following same classification principle, and previous examples only aim to show that despite low precision of estimates (large $d$ values), the approach adopted herein is able to produce reliable inputs that may be exploited in targeting and prioritization processes. Moreover, previous results can be depicted in maps, which allows for an easy interpretation (Figures 9 and 10).

Table 4 Categorization of bairros from Manhiça (Mozambique) in relation to use of sanitation infrastructure

\begin{tabular}{|c|c|c|c|c|c|c|}
\hline & Rank & $p_{i}$ & $\mathrm{pl}_{\mathrm{l}, \mathrm{i}}$ & $p_{u, i}$ & $\begin{array}{c}\text { Uniform } \\
\text { categorization }\end{array}$ & $\begin{array}{c}\text { Alternative } \\
\text { Categorization }\end{array}$ \\
\hline Ribjene & 1 & 0,013 & 0,000 & 0,072 & High Priority & High Priority \\
\hline Mitilene & 2 & 0,067 & 0,022 & 0,149 & High Priority & High Priority \\
\hline Chibucutso & 3 & 0,080 & 0,030 & 0,166 & High Priority & High Priority \\
\hline Balocuene & 4 & 0,103 & 0,045 & 0,192 & High Priority & High Priority \\
\hline Chibututuine & 5 & 0,115 & 0,054 & 0,208 & High Priority & High Priority \\
\hline Cambeve & 6 & 0,208 & 0,124 & 0,315 & High Priority & Priority \\
\hline Tsá-Tsé & 7 & 0,218 & 0,132 & 0,326 & High Priority & Priority \\
\hline Timaquene & 8 & 0,229 & 0,137 & 0,344 & High Priority & Priority \\
\hline Matadouro & 9 & 0,333 & 0,229 & 0,452 & Priority & Low Priority \\
\hline Ribangue & 10 & 0,372 & 0,265 & 0,489 & Priority & Low Priority \\
\hline Mulembja & 11 & 0,373 & 0,264 & 0,493 & Priority & Low Priority \\
\hline Wenela & 12 & 0,440 & 0,325 & 0,559 & Priority & Low Priority \\
\hline Maciana (includes Maragra) & 13 & 0,533 & 0,450 & 0,615 & Priority & Lowest Priority \\
\hline Manhiça Sede & 14 & 0,587 & 0,467 & 0,699 & Priority & Lowest Priority \\
\hline
\end{tabular}

Notes: a) $a=0.05$ (95\% confidence); b) Three bairros are excluded from the analysis since the sample of HHs is not adequate to achieve required statistical precision (Nhambi, Chafutene, Magaba)

In those locations where sanitation coverage is lowest and open defecation is widespread, the coordination of initiatives to support new construction of facilities, the implementation of social sanitation marketing strategies or the launch of total sanitation campaigns, such as those focused on the Community Led Total Sanitation (CLTS) approach (Kar and Chambers, 2008), would emerge as potential remedial actions. They all would trigger a movement on the sanitation ladder. 
Table 5 Categorization of bairros from Manhiça (Mozambique) in relation to the practice of open defecation

\begin{tabular}{lcccccc}
\hline & Rank & $\mathbf{p i}_{\mathbf{i}}$ & $\mathbf{p l}_{\mathrm{l}, \mathrm{i}}$ & $\mathbf{p}_{\mathrm{u}, \mathrm{i}}$ & $\begin{array}{c}\text { Uniform } \\
\text { categorization }\end{array}$ & $\begin{array}{c}\text { Alternative } \\
\text { Categorization }\end{array}$ \\
\hline Matadouro & 13 & 0,000 & 0,000 & 0,048 & Low Priority & Lowest Priority \\
Ribangue & 14 & 0,000 & 0,000 & 0,046 & Low Priority & Lowest Priority \\
Maciana (includes Maragra) & 12 & 0,007 & 0,000 & 0,037 & Low Priority & Lowest Priority \\
Manhiça Sede & 10 & 0,013 & 0,000 & 0,072 & Low Priority & Lowest Priority \\
Wenela & 11 & 0,013 & 0,000 & 0,072 & Low Priority & Lowest Priority \\
Cambeve & 9 & 0,026 & 0,003 & 0,091 & Low Priority & Lowest Priority \\
Tsá-Tsé & 8 & 0,038 & 0,008 & 0,108 & Low Priority & Lowest Priority \\
Balocuene & 7 & 0,051 & 0,014 & 0,126 & Low Priority & Lowest Priority \\
Chibucutso & 5 & 0,067 & 0,022 & 0,149 & Low Priority & Lowest Priority \\
Mulembja & 6 & 0,067 & 0,022 & 0,149 & Low Priority & Lowest Priority \\
Timaquene & 4 & 0,229 & 0,137 & 0,344 & Low Priority & Low Priority \\
Chibututuine & 3 & 0,244 & 0,153 & 0,354 & Low Priority & Low Priority \\
Mitilene & 2 & 0,347 & 0,240 & 0,465 & Priority & Priority \\
Ribjene & 1 & 0,613 & 0,494 & 0,724 & Priority & High Priority \\
\hline
\end{tabular}

Notes: a) $\alpha=0.05$ (95\% confidence); b) Three bairros are excluded from the analysis since the sample of HHs is not adequate to achieve required statistical precision

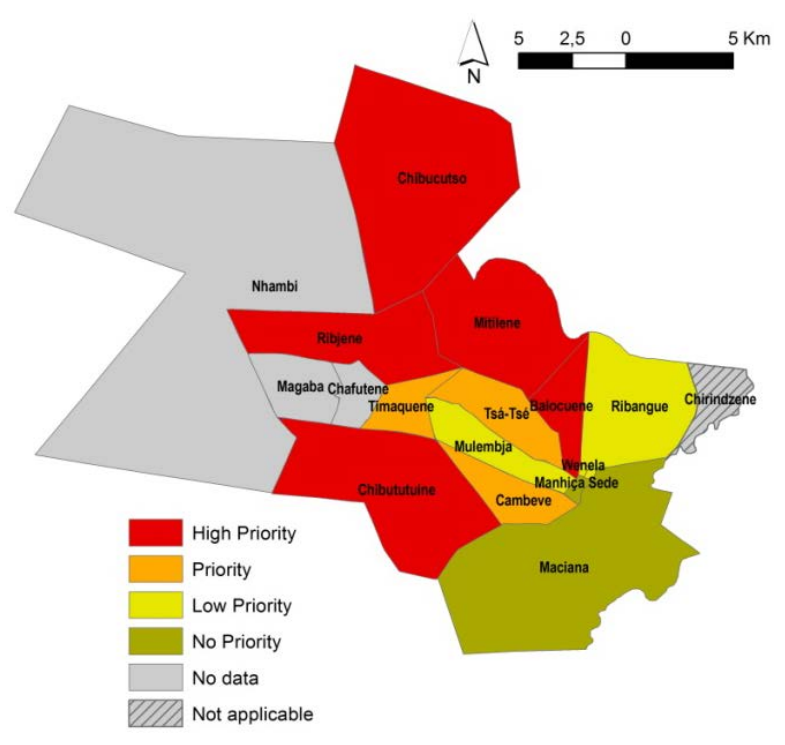

Figure 9 Improved Sanitation - Priorities (Manhiça, Mozambique)

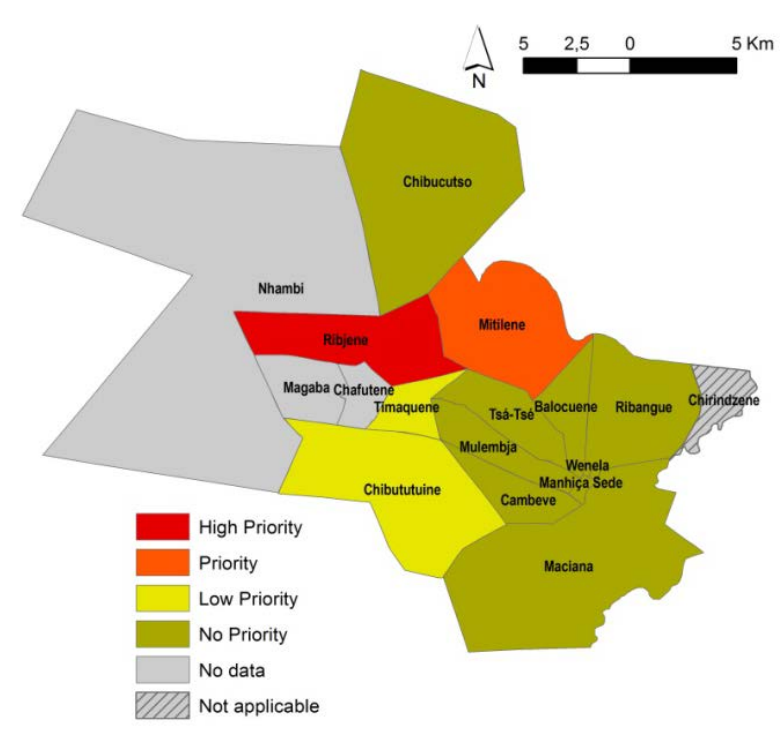

Figure 10 Open Defecation - Priorities (Manhiça, Mozambique)

Latrine sanitary conditions. The sanitary condition of the facilities may be assessed by means of four different proxies (cleanliness, presence of insects, smell and privacy). Figure 11 confirms that sanitation strategies should not only focus on the provision of the hardware, but on ensuring that it is safe, physically 
acceptable and hygienically maintained. In Tanzania, for instance, the district of Kibondo would do wise to facilitate and support campaigns for safe hygiene practices in the vicinity of the latrine, particularly in those highly prioritized wards.

Handwashing knowledge. It is well established that improvements in personal hygiene are of greatest likely benefit to health, and particularly handwashing with soap is one of the most effective ways to break the faecal-oral route of disease transmission (Curtis and Cairncross, 2003). An index for planning is thus proposed to assess the proportion of adults with adequate handwashing knowledge ${ }^{4}$.

It is observed from Figure 12 that the index scores relatively high in all divisions, i.e. seven out of ten adults know how to wash their hands. However, an evaluation (not shown here) of handwashing devices around the toilet points out that on average, a waterpoint is only found in less than 5\% of facilities; and soap is available in $2.1 \%$ of inspected latrines (Craven et al., 2013). This spotlights that while handwashing knowledge is adequate, handwashing behaviour is not. The launch of handwashing campaigns and other hygienerelated initiatives to promote hygiene education often become effective where handwashing behaviour is poor.

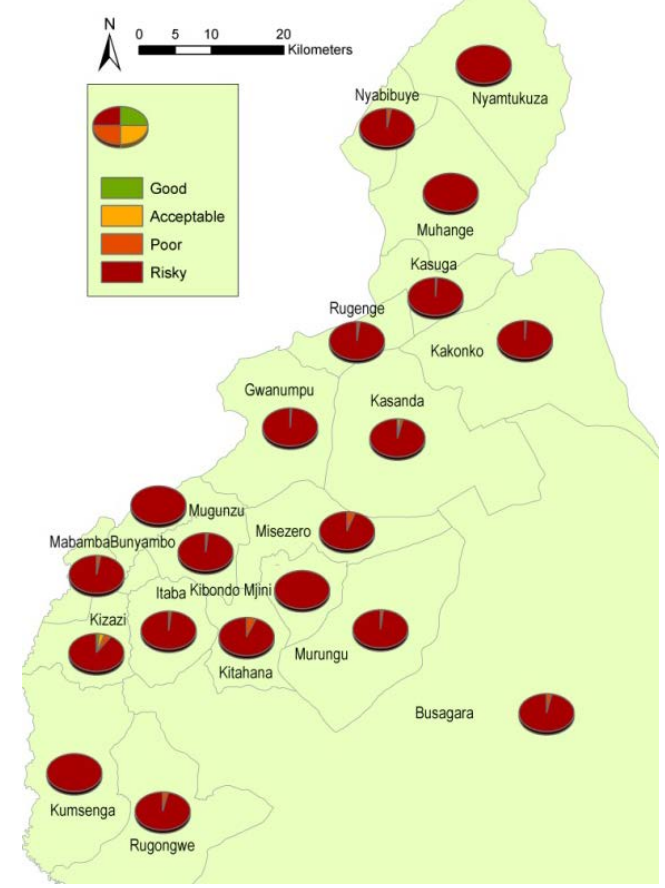

Figure 11 Latrine Sanitary Conditions Index (Kibondo District, Tanzania)

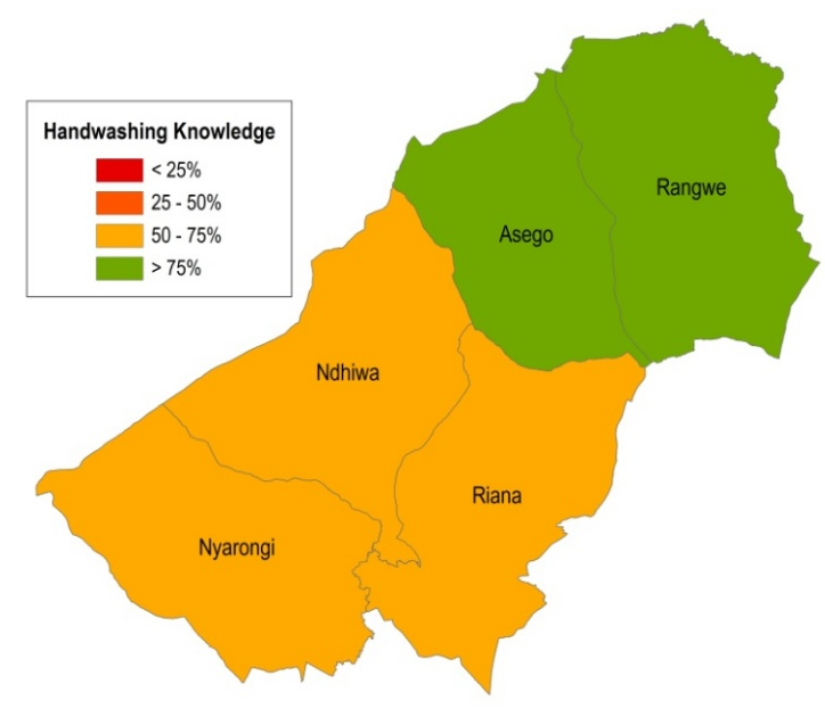

Figure 12 Handwashing Index (Homa Bay District, Kenya) 


\section{CONCLUSIONS AND WAYS FORWARD}

The delivery of water and sanitation services has shifted to decentralized approaches, where control over management and implementation activities moves to local governments. The underlying hypothesis is that local governments will be more responsive to the needs of the poor. Any prospect to develop more pro-poor policies, though, depends upon real efforts to strengthen the capacity of decentralized authorities. Integral to this emerging challenge, the aim of this paper is to show that local strategic planning may be strongly assisted by accurate and accessible information, which synthesised further, can guide the elaboration of development initiatives. The specific problems this study addresses therefore range from improving the availability of reliable information, to improving access to information for all relevant stakeholders, and in part, to encouraging the use of this information in decision-making processes.

Local authorities are currently faced with the pressing need to manage substantial amounts of resources. However, available information for decisionmaking is often too general (one access indicator at the very most) and out-ofdate (not updated), despite the role it can play to promote efficiency and transparency. In this paper, we show that by combining two extensively employed data collection methods, namely the waterpoint mapping and the household survey, comprehensive WASH baseline data can be produced to support targeting and prioritization, which are fundamental activities to poverty alleviation efforts. The proposed methodology offers an improvement on other similar methodologies: it collects data from two different information sources (waterpoints and households), and produces representative estimates at local level, where decisions are made. Most importantly, this is done in an efficient way, especially if the cost of collecting reliable data to formulate evidencebased interventions is compared with the cost of past investments that fail to deliver the expected benefits due to poor planning or inadequate design.

Another shortcoming is that even when information is available, there is no guarantee that it is adequately exploited for planning purposes. In an effort to address this, we propose a short battery of indices to highlight areas for improvement and ultimately guide appropriate action towards better service delivery. We also show that in decentralized contexts, where populations tend to be undersized, estimates may be produced with sufficient precision for use in targeting and prioritization processes. Finally, indices have been disseminated through league tables and priority maps to improve transparency and inclusiveness in the decision-making process. The data is thus processed and disseminated to produce simple policy messages that are easily understood by decision-makers, non-technical stakeholders and the recipient populations. 
In sum, the monitoring framework presented herein deals with the definition of prioritization and targeting mechanisms required to identify the sectors and the segments of population in which focus policy attention. It covers the monitoring cycle of data collection, data analysis and data dissemination; and provides reliable inputs for informed decision-making. The study falls short, however, of showing how the developed methodologies and tools may be applied in practice and integrated into existing monitoring structures at the local level. Among others, two specific challenges remain elusive, namely i) the upgrade of existing decision-making processes to enhance transparency and inclusiveness, and ii) the development of appropriate updating mechanisms.

There is indeed a need to upgrade, simplify and systematize systems and processes that support and regulate planning, targeting and prioritization (e.g. district operational guidelines, etc.). Today, these processes often lack transparency and accountability - can discriminate against particular population groups - and are typically fed by incomplete, inaccurate and outdated data - as previously discussed. In addition, they do not integrate in their basic configuration the various competing and often conflicting uses of water and sanitation services. A step forward in the improvement of the decision-making process would be the establishment of appropriate decision-support systems to guide decision-makers in i) evaluating decision options against multiple criteria, and in ii) choosing the most appropriate action. There is also the need to support and strengthen the information management and monitoring capacities of decision-makers in the use of the developed instruments, systems and processes. In the short term, multi-stakeholder alliances between governments, NGOs, academics and consultants may be well positioned to provide the necessary support. In the medium term, however, political will and commitment at all levels, i.e. from central government to local authorities, is imperative to enhance the process of turning monitoring data into valuable information, and in promoting the continued use of this information in decision-making. The ultimate goal should be to allow local governments make informed decisions autonomously, which implies that they are able to negotiate about the planning goals, to work together on an agreed strategy and to ultimately translate this into action.

In parallel, the monitoring framework needs to be rethought so that it can be regularly updated by local stakeholders with its own resources. The reliability of the data decreases with time, and good systems and processes may lead to misleading results if they are based on outdated data sets. It is noteworthy, on the one hand, that new technologies are leading to an exponential increase in the volume and types of data available, creating unprecedented possibilities for informing decision-making (Independent Expert Advisory Group on a Data 
Revolution for Sustainable Development, 2014). On the other hand, monitoring structures at the local level remain weak. The sector rarely has - compared to other sectors such as health and education - dedicated extension workers based at the local level who can systematically report on the functionality of water supply schemes and sanitation issues (WaterAid, 2010). In addition, high turnover of technical staff hinders the implementation of capacity development programs. And for water officers, auditing water points on a regular basis is logistically challenging because of the number and geographical dispersion of water supplies, because of a lack of road infrastructure, particularly during the wet season, and because of very limited operational budgets and resources available to them (transport, equipment, etc.). In the end, there is a trade-off between the scope and quality of the data required for decision-making support and the complexity of updating mechanisms (WaterAid, 2010). The design of a cheap, simple and effective monitoring system is desirable, at least, initially, which in turn brings about the need for a detailed estimate of the costs associated with data update. By and large, despite successful initiatives of simple systems for data update based exclusively on local means, as one case study reported in Tanzania (Jiménez and Pérez Foguet, 2010b), the limited resources and capacities of local stakeholders is a major weakness. In data collection, communities can contribute to the achievement of sustainable updating mechanisms, though this should not draw attention away from the responsibilities of local governments (WaterAid, 2011). In data analysis, rankings and league tables can be easily computed through pre-programmed spreadsheets, but GIS-related skills are not be easily found at local level. That being said, even despite the increased use of technologies in handling data and information, to ignore the need for external support may be counterproductive in the short run. From the government side, one alternative may be the establishment of regional units that provide support with data collection and data analysis. And since local capacities are unlikely to increase significantly in the short term, capacity development programmes should be included in the national capacity development framework.

These two challenges suggest the way forward. 


\section{NOTES}

1 The types of waterpoints considered as improved are consistent with those accepted internationally by the WHO/UNICEF Joint Monitoring Programme (WHO/UNICEF 2006), where definition of improved is technology-based.

${ }^{2}$ The "design effect" is an adjustment that measures the efficiency of the sample design, and is calculated by the ratio of the variance of an estimator to the variance of the same estimator computed under the assumption of simple random sampling.

${ }^{3}$ Sanitation technologies are considered as providing adequate access to sanitation as long as they are private (but not shared / public) and hygienically separate human faeces from human contact (improved). Based on these two requirements, sanitation coverage is presented as a four-step ladder that distinguishes between: i) open defecation; ii) unimproved sanitation; iii) shared improved sanitation; and iv) improved sanitation. Only last step is considered as "coverage" (Joint Monitoring Programme 2008).

${ }^{4}$ Assessment of handwashing behaviour requires specific evaluation techniques, which were out of the scope of this study.

\section{ACKNOWLEDGEMENTS}

The authors would like to extend thanks to all families who participated in the study. Further thanks go to ONGAWA and to Kibondo District Water Department for their support to undertake the survey in Kibondo District, in Tanzania; to UNICEF (Kenya Country Office) and to Homa Bay District Water Office and District Public Health Office, in Kenya; and to UN Habitat (Country Office) and the Municipality of Manhiça, in Mozambique. This study has been partially funded by the Centre de Cooperació per al Desenvolupament (Universitat Politècnica de Catalunya) and the Agencia Española de Cooperación Internacional para el Desarrollo [reference 11-CAP2-1562]. We also acknowledge three anonymous reviewers for suggestions to improve the manuscript.

\section{REFERENCES}

Blair, H., 2000. Participation and Accountability at the Periphery: Democratic Local Governance in Six Countries. World Dev. 28, 21-39.

Bostoen, K., 2002. Measuring Access and Practice: Designing a Survey Methodology for the Hygiene, Sanitation and Water Sector. Dep. Infect. Trop. Dis. London School of Hygiene and Tropical Medicine, London.

Breslin, E.D., 2010. Rethinking Hydro-Philanthropy: Smart Money for Transformative Impact. Water for People, Denver.

Cairncross, S., Feachem, R.G., 1993. Environmental Health Engineering in the Tropics: An Introductory Text, 2nd ed. John Wiley \& Sons, Chichester.

Cairncross, S., Hunt, C., Boisson, S., Bostoen, K., Curtis, V., Fung, I.C., Schmidt, W.P., 2010. Water, sanitation and hygiene for the prevention of diarrhoea. Int J Epidemiol 39 Suppl 1, i193-205. doi:dyq035 [pii] 10.1093/ije/dyq035

Cortinovis, I., Vella, V., Ndiku, J., 1993. Construction of a socio-economic index to facilitate analysis of health data in developing countries. Soc. Sci. Med. 36, 1087-1097. 
Craven, J., Giné Garriga, R., Jiménez, A., Pérez Foguet, A., 2013. Introducing hygiene elements into sanitation monitoring, in: 36th WEDC International Conference. Water, Engineering and Development Centre. Loughborough University, Nakuru, Kenya.

Crook, R.C., 2003. Decentralisation and poverty reduction in Africa: The politics of local-central relations. Public Adm. Dev. 23, 77-88. doi:10.1002/pad.261

Curtis, V., Cairncross, S., 2003. Effect of washing hands with soap on diarrhoea risk in the community: a systematic review. Lancet Infect. Dis. 3, 275-281.

Devas, N., Grant, U., 2003. Local government decision-making - Citizen participation and local accountability: Some evidence from Kenya and Uganda. Public Adm. Dev. 23, 307-316. doi:10.1002/pad.281

Dreibelbis, R., Winch, P.J., Leontsini, E., Hulland, K.R.S., Ram, P.K., Unicomb, L., Luby, S.P., 2013. The Integrated Behavioural Model for Water, Sanitation, and Hygiene: a systematic review of behavioural models and a framework for designing and evaluating behaviour change interventions in infrastructure-restricted settings. BMC Public Health 13, 1015. doi:10.1186/1471-2458-13-1015

Esrey, S.A., Potash, J.B., Roberts, L., Shiff, C., 1991. Effects of improved water supply and sanitation on ascariasis, diarrhoea, dracunculiasis, hookworm infection, schistosomiasis, and trachoma. Bull World Heal. Organ 69, 609-621.

Fewtrell, L., Kaufmann, R.B., Kay, D., Enanoria, W., Haller, L., Colford, J.J.M., 2005. Water, sanitation, and hygiene interventions to reduce diarrhoea in less developed countries: a systematic review and meta-analysis. Lancet Infect. Dis. 5, 42-52.

Ghosh, M., Rao, J.N.K., 1994. Small Area Estimation: An Appraisal. Stat. Sci. doi:10.1214/ss/1177010647

Giné Garriga, R., Jiménez, A., Pérez Foguet, A., 2013a. Water-sanitation-hygiene mapping: An improved approach for data collection at local level. Sci. Total Environ. 463-464, 700-711. doi:http://dx.doi.org/10.1016/j.scitotenv.2013.06.005

Giné Garriga, R., Jiménez, A., Pérez Foguet, A., 2013b. The issue of the design effect in water, sanitation and hygiene studies, in: 36th WEDC International Conference. Water, Engineering and Development Centre. Loughborough University, Nakuru, Kenya.

Giné Garriga, R., Pérez Foguet, A., 2013. Water, sanitation, hygiene and rural poverty: issues of sector planning and the role of aggregated indicators. Water Policy 15, 1018-1045. doi:10.2166/wp.2013.037

Government of United Republic of Tanzania, 2006. "National rural water supply and sanitation programme (NRWSSP).

Grosh, M.E., 1997. The policymaking uses of multitopic household survey data: A primer. World Bank Res. Obs. 12, 137-160.

Howard, G., 2002. Water quality surveillance: a reference manual. Water, Engineering and Development Centre. Loughborough University, Leicestershire.

Howard, G., Bartram, J., 2003. Domestic Water Quantity, Service Level and Health. World Health Organization, Geneva.

Hunter, P.R., Zmirou-Navier, D., Hartemann, P., 2009. Estimating the impact on health of poor reliability of drinking water interventions in developing countries. Sci. Total Environ. 407, 2621-2624.

Independent Expert Advisory Group on a Data Revolution for Sustainable Development, 2014. A World That Counts: Mobilising The Data Revolution for Sustainable Development. New York and Geneva.

Jiménez, A., Pérez Foguet, A., 2012. Quality and year-round availability of water delivered by improved water points in rural Tanzania: effects on coverage. Water Policy 14, 509-523. doi:10.2166/wp.2011.026

Jiménez, A., Pérez Foguet, A., 2011. Implementing pro-poor policies in a decentralized context: the case of the Rural Water Supply and Sanitation Program in Tanzania. Sustain. Sci. 6, 37-49. doi:10.1007/s11625-010-0121-1

Jiménez, A., Pérez Foguet, A., 2010a. Building the role of local government authorities towards the achievement of the human right to water in rural Tanzania. Nat. Resour. Forum 34, 93-105.

Jiménez, A., Pérez Foguet, A., 2010b. Challenges for Water Governance in Rural Water Supply: Lessons Learned from Tanzania. Int. J. Water Resour. Dev. 26, 235-248. doi:10.1080/07900621003775763 
Jiménez, A., Perez-Foguet, A., 2011. The relationship between technology and functionality of rural water points: evidence from Tanzania. Water Sci. Technol. 63, 948-955. doi:10.2166/wst.2011.274

Joint Monitoring Programme, 2014. Progress on Sanitation and Drinking Water: 2014 Update, Joint Monitoring Programme for Water Supply and Sanitation. WHO / UNICEF, Geneva / New York.

Joint Monitoring Programme, 2011. Report of the First Consultation on Post-2015 Monitoring of Drinking-Water and Sanitation. WHO / UNICEF Joint Monitoring Programme for Water Supply and Sanitation (JMP), Berlin.

Joint Monitoring Programme, 2008. Progress on Drinking Water and Sanitation: Special Focus on Sanitation, Joint Monitoring Programme for Water Supply and Sanitation. WHO I UNICEF, Geneva / New York.

Joint Monitoring Programme, 2006. Core questions on drinking-water and sanitation for household surveys. WHO / UNICEF, Geneva / New York.

Kar, K., Chambers, R., 2008. Handbook on Community-Led Total Sanitation. Plan UK and Institute of Development Studies (IDS), Brighton.

Kayser, G., Moriarty, P., Fonseca, C., Bartram, J., 2013. Domestic Water Service Delivery Indicators and Frameworks for Monitoring, Evaluation, Policy and Planning: A Review. Int. J. Environ. Res. Public Health 10, 4812-4835.

Kish, L., 1980. Design and Estimation for Domains. Statistician 29, 209-222. doi: $10.2307 / 2987728$

Luby, S.P., Agboatwalla, M., Feikin, D.R., Painter, J., Billhimer, W., Altaf, A., Hoekstra, R.M., 2005. Effect of handwashing on child health: A randomised controlled trial. Lancet 366, 225-233. doi:10.1016/S0140-6736(05)66912-7

Pickering, A.J., Davis, J., 2012. Freshwater availability and water fetching distance affect child health in sub-Saharan Africa. Environ. Sci. Technol. 46, 2391-2397. doi:10.1021/es203177v

Rao, J.N.K., 2003. Small Area Estimation, Wiley series in survey methodology.

Scott, R., Cotton, A.P., Govindan, B., 2003. Sanitation and the Poor. WELL Resource Centre (WEDC, LSHTM \& IRC), Loughborough, London \& Delft .

Steiner, S., 2007. Decentralisation and poverty: Conceptual framework and application to Uganda. Public Adm. Dev. 27, 175-185. doi:10.1002/pad.445

United Nations Children's Fund, 2006. Multiple Indicator Cluster Survey Manual 2005. UNICEF, Division of Policy and Planning, New York.

WaterAid, 2011. Sustainability framework. WaterAid, London.

WaterAid, 2010. Water point mapping in East Africa. Based on a strategic review of Ethiopia, Tanzania, Kenya and Uganda. WaterAid, London.

WaterAid, 2009. Sustainability and equity aspects of total sanitation programmes. A study of recent WaterAid-supported programmes in three countries. Global synthesis report. WaterAid, London.

WaterAid, ODI, 2005. Learning for Advocacy and Good Practice - WaterAid Water Point Mapping. Overseas Development Institute, London. 